\title{
A Retrospective Study on Different Treatment Modalities of Hepatocellular Carcinoma in Assiut Governorate
}

\author{
Nada Hassan Salah M.B.B.CH ${ }^{1}$, Samir Shehata Mohammed MD ${ }^{2}$, Hoda Hassan Eisa MD ${ }^{3}$, \\ Ola Nabih Abdel Fattah MD ${ }^{4}$
}

Department of Clinical Oncology Assiut University, Assiut, Egypt

\begin{abstract}
Introduction: the management of HCC in assiut governorate is affected by many factors that would affect the choice and effectiveness of treatment. Aim of the work: to identify the different lines of management of HCC and factors associated with them. Methods: retrospective study that included 146 patients with primary hepatocellular carcinoma (HCC), admitted to Assiut university hospital and El Rajhi hospital during the period from January 2012 to December 2014. Results: the main lines of HCC management included 5 lines: surgery (resection/transplantation), local ablation, TACE, chemotherapy and Best supportive care. The most significant factors that affected treatment choice and results were Child pugh score, primary tumor size and multiplicity. Conclusion: The best cure rate was found in small or single lesions or child pugh score A managed with surgical resection. TACE was the most widely used modality.lesions more than $5 \mathrm{~cm}$ or multiple lesions or child pugh score $B$ or $C$ were associated with chemotherapy and best supportive care.
\end{abstract}

Keywords: hepatocellular carcinoma, epidemiology, upper Egypt, treatment modalities

\section{Introduction}

Hepatocellular carcinoma is the fifth most common type of cancer and the third most common cause of cancer-related mortality in the world. Over $80 \%$ of HCC develops in cirrhotic liver, and is mainly attributable to chronic viral infection with hepatitis B or C. The great majority of HCC cases occur in developing countries with a very high incidence in Asia and Sub-Sahara Africa. However, its incidence is increasing in Japan, United States, and other western countries with the rise of infection with hepatitis $\mathrm{C}$ (Nordenstedtet al., 2010 and Yang and Roberts, 2010).

HCC has a rising incidence in Egypt mostly due to high prevalence of viral hepatitis and its complications. It ranks second and sixth most common cancer among men and women respectively (Omar et al., 2013).

Theoretically, the best treatment for HCC is liver transplantation, which offers the potential to both resect the entire potentially tumor-bearing liver and eliminate the cirrhosis if present (Majnoet al., 1997, Belghiti,2005, Ravaioliet al., 2008, Choti,2009 and De Luna et al., 2009)

Liver resection has generally been accepted as the first treatment of choice for HCC.however,the associated cirrhosis limits the extent of surgery and increases the risk of postoperative liver failure and recurrence.(Facciutoet al., 2009 and Belghitiet al., 2003).

The limited treatment options for patients with unresectable HCC have led to the emergence of other liver directed therapies including thermal ablative techniques (radiofrequency ablation [RFA] and microwave), percutaneous ethanol injection (PEI), cryoablation, local administration of cytostatic drugs, and intrarterial embolization techniques such as selective intrarterialradioembolization embolization (TAE), and transarterial chemoembolization (TACE) (Schwartz et al., 2007).

The present study is an epidemiologic retrospective one that aimed at identification of different treatment modalities of hepatocellular carcinoma in Assiut Governorate and to identify the factors that affect the choice and effectiveness of each modality.

\section{Patients and Methods}

The present study is an epidemiologic retrospective one that aimed at determining the bulk of the problem in our area and to identify the results of different treatment modalities.It was carried out on all patients presented to liver hospital and clinical oncology unit in Assuit University Hospital and were diagnosed as HCC during the period from 2012 to 2014

All patients 'files were reviewed for clinical, laboratory, imaging data and staging according to Child-Pugh classification system, The different modalities of treatment were reviewed and recorded includingSurgery For resectable tumors and locoregional treatment for unresectable tumorsandmetastatic disease.

All files also were reviewed for assessment after the end of treatment and the response were defined according to WHO criteria as: complete response (CR), partial response $(\mathrm{PR})$, minimal response (MR)and progressive disease (PD).

The present study included 146 patients: 111 male and 35 female (aged between 46 and 77 years) with primary hepatocellular carcinoma (HCC), at Assiut university hospital and El Rajhi hospital during the period from January 2012 to December 2014, diagnosed by Triphasic spiral CT scan based on their early arterial enhancement and late portal venous washout. 


\section{International Journal of Science and Research (IJSR) \\ ISSN (Online): 2319-7064 \\ Index Copernicus Value (2015): 78.96 | Impact Factor (2015): 6.391}

\section{Results}

As shown in table1, The majority of patients were males (79.2\%); Patients were equally distributed around the age of $60 \mathrm{yrs}$ (52\% above 60 and $48 \%$ were below); Hepatitis C-V was associated with more than $90 \%$ of cases; and Child Pugh score of $\mathrm{A}$ in $60 \%$ of cases and the primary diagnosis of a single lesion was made in $60 \%$ of cases.

Table 1: General features of study cases(n: 146)

\begin{tabular}{|l|c|c|}
\hline & No. & \% \\
\hline Age groups & & \\
\hline$\leq 60$ years & 76 & 52.05 \\
\hline$>60$ years & 70 & 47.9 \\
\hline Sex & & \\
\hline Male & 111 & 79.2 \\
\hline Female & 35 & 20.8 \\
\hline Tumor size & & \\
\hline$\leq 5$ cm & 121 & 82.8 \\
\hline$>5$ cm & 25 & 17.2 \\
\hline Hepatitis & & \\
\hline HCV & 121 & 82.2 \\
\hline HBV & 13 & 8.9 \\
\hline Mixed & 6 & 4.1 \\
\hline Negative & 6 & 4.1 \\
\hline Cirrhosis & & \\
\hline Yes & 133 & 91.05 \\
\hline No & 13 & 8.9 \\
\hline Child Pugh score & & \\
\hline A & 88 & 60.27 \\
\hline B & 51 & 34.9 \\
\hline C & 7 & 4.7 \\
\hline AFP & & \\
\hline$\leq 400$ & 82 & 56.1 \\
\hline$>400$ & 64 & 43.8 \\
\hline Single/Multiple & & \\
\hline Single & 87 & 59.58 \\
\hline Multiple & & 40.4 \\
\hline
\end{tabular}

In table 2 and in figure 1; the frequency of different treatment options is displayed where TACE was the most commonly used option followed by local ablation and chemotherapy

Table 2: Frequency distribution of treatments

\begin{tabular}{|c|c|c|}
\hline Treatments & $N$ & $\%$ \\
\hline Resection/transplantation & 20 & 14 \\
\hline Local ablation & 35 & 23.9 \\
\hline TACE & 40 & 26.9 \\
\hline Chemotherapy (weekly gemzar) & 31 & 21.2 \\
\hline Best supportive care & 20 & 14 \\
\hline
\end{tabular}

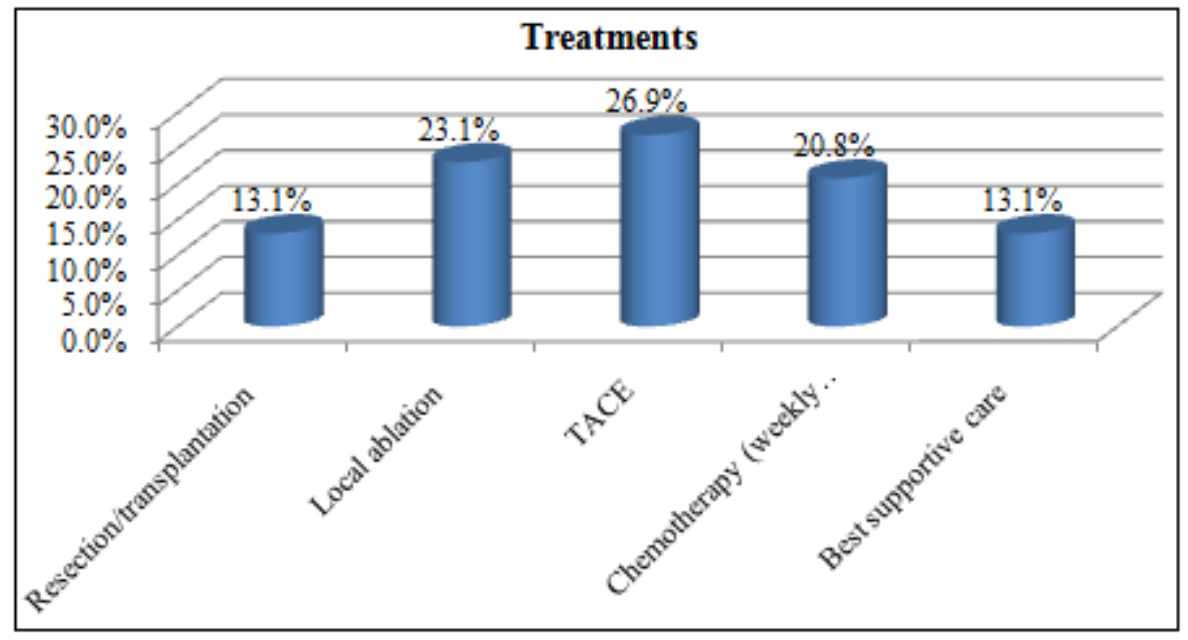

Figure 1: Frequency distribution of treatment

The results of different treatment options are shown in figure 2 where complete response was significantly associated only with surgical resection while progressive disease was most likely with best supportive care and chemotherapy.

\section{Volume 6 Issue 7, July 2017 www.ijsr.net}


International Journal of Science and Research (IJSR)

ISSN (Online): 2319-7064

Index Copernicus Value (2015): 78.96 | Impact Factor (2015): 6.391

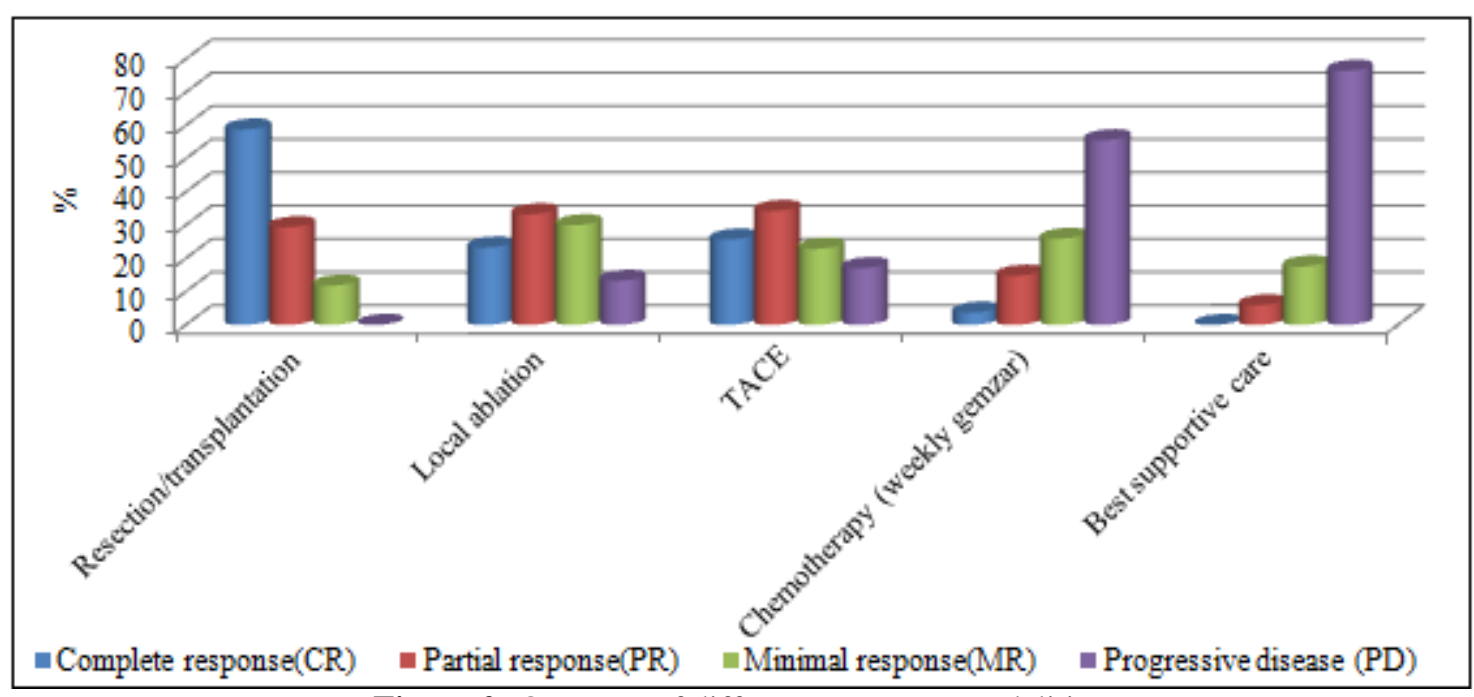

Figure 2: Outcome of different treatment modalities

There is high statistically significant difference between child pugh score of the patient and TACE as a modality of treatment $(\mathrm{P}$ value 0,0001$)$ but no statistically significant difference with other modalities of treatment (table 3)

Table 3: Relation between Child Pugh score and different treatment modalities

\begin{tabular}{|c|c|c|c|c|c|c|c|c|}
\hline & \multicolumn{6}{|c|}{ Child pugh score } & \multirow{3}{*}{ P. value } \\
\cline { 2 - 8 } & $\mathrm{A}(\mathrm{t} ; 88)$ & \multicolumn{3}{|c|}{$\mathrm{B}(\mathrm{t} ; 51)$} & \multicolumn{2}{c|}{$\mathrm{C}(\mathrm{t} ; 7)$} & \multirow{2}{*}{} \\
\cline { 2 - 8 } & No. & $\%$ & No. & $\%$ & No. & $\%$ & \\
\hline Resection/transplantaion & 13 & 14.8 & 7 & 13.7 & 0 & 0.0 & 0.551 \\
\hline Local ablation & 22 & 25 & 12 & 23.5 & 1 & 14.3 & 0.812 \\
\hline TACE & 27 & 30.7 & 13 & 25.4 & 0 & 0.0 & $0.0001 * *$ \\
\hline $\begin{array}{c}\text { Chemotherapy (weekly } \\
\text { gemzar) }\end{array}$ & 21 & 23.8 & 10 & 19.7 & 0 & 0.0 & 0.312 \\
\hline Best supportive care & 5 & 5.7 & 9 & 17.6 & 6 & 85.7 & 0.231 \\
\hline
\end{tabular}

There is high statistically significant difference between size of the tumor (more or less than $5 \mathrm{~cm}$ ) and local ablation $(\mathrm{P}$ value 0.001$)$, also significant with best supportive care $(P$ value 0.001 ) as modalities of treatment. but no statistically significant difference with other modalities (table 4)

Table 4: Relation between tumor size and treatment options:

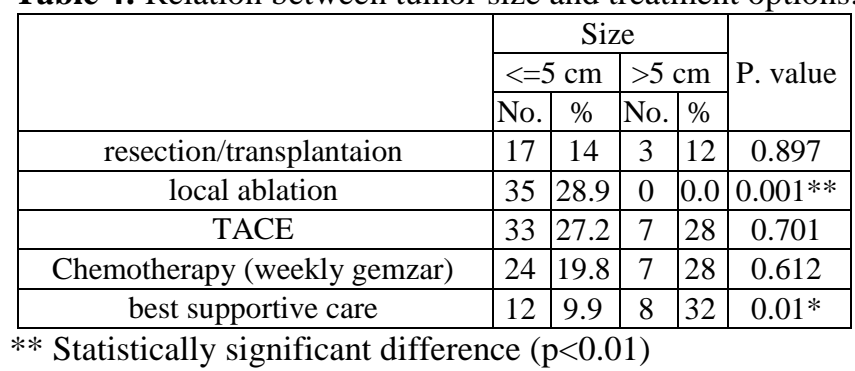

In single lesion/cases the most commonly used modalities were TACE and local ablation, while chemotherapy and best supportive care were least used. In cases with multiple lesions: local ablation, chemotherapy and best supportive care were most commonly used while resection and TACE were the least used. (table 5)
Table 5: Relation between tumor multiplicity and treatment modalities

\begin{tabular}{|c|c|c|c|c|c|}
\hline \multirow{2}{*}{} & \multicolumn{3}{|c|}{ Single/multiple } & \multirow{2}{*}{ P. value } \\
\cline { 2 - 6 } & Single & \multicolumn{2}{c|}{ Multiple } & \\
\cline { 2 - 6 } & No. & $\%$ & No. & $\%$ & \\
\hline Resection/transplantaion & 14 & 16 & 6 & 10.2 & 0.369 \\
\hline Local ablation & 22 & 25.3 & 13 & 22.03 & 0.355 \\
\hline TACE & 35 & 40.3 & 5 & 8.4 & $<0.001 * *$ \\
\hline Chemotherapy (weekly gemzar) & 8 & 9.2 & 23 & 40 & $<0.001 * *$ \\
\hline Best supportive care & 8 & 9.2 & 12 & 20.4 & $0.016^{*}$ \\
\hline
\end{tabular}

\section{Discussion \& Conclusion}

In the present study about $52 \%$ of the patients were between 50 and 60 years old, this generally agreed with (El-seraget al., 2007) which stated that Hepatocellular carcinoma rarely occurs before the age of 40 years and reaches a peak at approximately 70 years of age, also agreed with (Mohammed et al., 2000and Shaker et al., 2013).

There was a figure of $79 \%$ males which is generally agreed with $(\boldsymbol{W H O}, 2008)$ which stated that Liver cancer is the fifth most common cancer in men worldwide $(523,000$ cases per year, $7.9 \%$ of all cancers) and the seventh in women (226,000 cases per year, 6.5\% if all cancers). Also agreed with (El-Serag and Rudolph, 2007) which stated that Rates of liver cancer among men are two to four times as high as the rates among women.Shaker et al., (2013) also agrees with our study. This is mostly explained by higher incidence of HCV in males than females.

At admission, about $91 \%$ of the caseshad liver cirrhosis which agreed with Sangiovanniet al., (2006) who stated that All etiologic forms of cirrhosis may be complicated by tumor formation, and that the risk is higher in patients with hepatitis infection. Overall, one-third of cirrhotic patients will develop HCC during their lifetime, Velasquez et al., (2003) and El Serag(2001) also agrees with our study.

On the other hand, in our study $82 \%$ of the cases had haptitis C, $9 \%$ hepatitis $\mathrm{B}, 4 \%$ mixed, those percentages were different from worldwide studies as according to (EASL EROTC clinical practice guidlines, 2012): approximately 


\section{International Journal of Science and Research (IJSR) \\ ISSN (Online): 2319-7064}

Index Copernicus Value (2015): 78.96 | Impact Factor (2015): 6.391

$54 \%$ of cases worldwide can be attributed to HBV infection (which affects 400 million people globally) while $31 \%$ can be attributed to $\mathrm{HCV}$ infection (which affects 170 million people), leaving approximately $15 \%$ associated with other causes.

Reviewing the literature agrees with the impression that the underlying type of viral infection type differs widely in different zones of the world according to different communities characteristics:

$\mathrm{HCV}$ infection confers the highest risk of HCC in patients with cirrhosis, with an annual incidence ranged between $2 \%$ and $8 \%$ (Bruix and Sherman, 2005). While the incidence of HBV-related HCC has decreased after the initiation of a universal vaccination program (El-Serag 2011).

In our study: In about $60 \%$ of cases child pugh score was A, while it was B in about $35 \%, \mathrm{C}$ in about $5 \%$ of the cases, this can simply be explained as the majority of cases were studied at el Rajhi hospital which were admitted to hospital with criteria consistent with planning for major or minor surgical procedure that included patients in relatively good general condition or in early stages of disease.

AFP was less than 400 in $56 \%$ of the cases of the present study,most worldwide studies recommend AFP level with high cutoff points as $400 \mathrm{ng} / \mathrm{ml}$ to be a good prognostic predictor in HCC patients only if dependent on other factors as tumor size (large cutoff as $5 \mathrm{~cm}$ )(Huoet al., 2004)

Single lesions were found in about $60 \%$ of cases and multiple lesions in $40 \%$ and this agreed with Kumar et al., (2008)\&Shaker et al., (2013) which stated that single lesion is the most common presentation in HCC with almost similar percentages.

In the present study we found highly significant difference between tumor size and $\operatorname{sex}(p$ value 0.001$)$ this could be explained by increased exposure to risk factors in males; hepatitis C or B, smoking, alcohol,Yu MW et al., (2005)also genetics and sex hormonesas estrogen and androgen were found to play a role in hepatocarcinogenesis(Nagasue $\boldsymbol{N}$ et al., 1985).It maybe also explained by the common belief that males in poor communities are usually late complainers than women.

Ahighly significant difference was found between tumor size and Child Pugh score ( $\mathrm{p}$ value 0.009).butno statistically significant difference between multiplicity of lesion and either hepatitis or child pugh score.

In our study, there was no statistically significant difference between alpha feto protein neither with tumor size nor multiplicity. This was in disagreement with other studies as that suggests strong correlation between AFP and size $>5 \mathrm{~cm}$ (Abbasiet al., 2012)

As regards different treatment modalities applied in Assiut university hospitals, we found that; TACE and Local ablation were the most common modalities of treatment $(27 \%$ and $23 \%$ ) while the least commonly used modality was surgery and BSC (13\% for each) on the other hand $21 \%$ of HCC patients were subjected to chemotherapy "weekly gemzar". This generally agreed with Weledjiet al., (2014) who states that local ablation (using either radiofrequency ablation or percutaneous ethanol injection) and TACE are the $1^{\text {st }}$ treatment option in HCC patients specially in cases with early stages HCC but not suitable for surgery and those cases represent the largest proportion of HCC patients, and also safe and effective option.

In our study we found that complete response was the most frequent result of resection/transplantation arm $(58 \%$ of the patients) followed by TACE and local ablation this generally agreed with the report of theJournal of Hepatology(2012) with some limitations: it stated that liver resection is the treatment of choice for patients with maintained underlying liver structure and function and for patients with solitary tumors, if these conditions were applied complete response will be achieved in most cases, however the risk of recurrence is high on the long term .While with local ablation with radiofrequency or percutaneous ethanol injection it was considered the standard care for early stage patients with tumors not suitable for surgery,radiofrequency ablation is recommended in most instances as the main ablative therapy in tumors less than $5 \mathrm{~cm}$. Ethanol injection is recommended in cases where radiofrequency ablation is not technically feasible(around 10-15\%). In tumors $<2 \mathrm{~cm}$, with early Child pugh score, both techniques achievecomplete responses in more than $90 \%$ of cases with good long-term outcome. Whether they can beconsidered as competitive alternatives to resection is uncertain

Progression response was most commonly met with Best Supportive Care arm (76.5\%) followed by chemotherapy $(55 \%)$ while it was $0 \%$ with resection arm. Journal of Hepatology(2012)stated that best supportive careusually results in disease progression due to the original advanced disease.thus,it can't be involved in trials. Concerning chemotherapy, Journal of Hepatologyalso agreed with our study in that chemotherapy is not a recommended modality of treatment for HCC, the only standard systemic treatment is Sorafenib which couldn't be included in our study due to financial issues.

In this study, According to Child Pugh score the different treatment modalities were almost similarily used in Child's $\mathrm{A}$ and $\mathrm{B}$ while in Child's $\mathrm{C}$ the best supportive care was significantly commonly used.this was in agreement with Journal of Hepatology(2012) which clarified that almost all modalities of treatment whether surgery, local ablation, TACE or even systemic chemotherapy requires relatively good general condition and early Child's score $(\mathrm{A}, \mathrm{B})$ to be able to get satisfactory outcome, for patients with Child's score $\mathrm{C}$, the only possible treatment option is Best supportive care.

In our study there was high statistically significant difference between tumor size of $5 \mathrm{~cm}$ or less and local ablation: this is simply explained by the fact that in the interventional procedure of local ablation patients are selected preoperatively to have tumor size less than $5 \mathrm{~cm}$. On the other hand a significant value ( $\mathrm{P}$ value 0.001$)$ with best supportive care and tumor sizes larger than $5 \mathrm{~cm}$ is expected with this line. Also there was no statistically significant 


\section{International Journal of Science and Research (IJSR) \\ ISSN (Online): 2319-7064}

Index Copernicus Value (2015): 78.96 | Impact Factor (2015): 6.391

difference with other modalities which were equally used in tumors smaller or larger than $5 \mathrm{~cm}$ : this statistical analysis maybe affected by the fact that cases with tumors larger than $5 \mathrm{~cm}$ were of much less number than cases with smaller tumors (21 vs 118).

The current study shows that in single lesion/cases the most commonly used modalities were TACE and local ablation,this disagreed with (EASL-EORTC Clinical Practice Guidelines, 2012) which approved liver resection as the first treatment choice for solitary tumor lesions, this disagreement maybe explained by the fact that in our community locoregional procedures are more safe and less complicated.In cases with multiple lesions, local ablation and chemotherapy were most commonly used. This agreed with (EASL-EORTC Clinical Practice Guidelines,2012) which stated that locoregional treatment is the available option for multinodular tumor cases, chemotherapy is not recommended as a treatment choice in the guidelines but systemic treatment (sorafenib) is given tocases with tumor lesions beyond locoregional procedures, sorafenib couldn't be administered by patients in our study due to financial issues.

In Conclusion; The available treatment modalities in our area depend on many factors such as tumour size; multiplicity; Child-Pugh score and presence hepatitis in addition to the availability of surgical treatment options like liver-transplantation. As an area of low resources and low socio-economic standards: this seems to play an important role and would affect the timing of HCC detection;progress of investigations and ability to provide our patients with optimum care as much as can be done: finally all these factors would add to the prognostic module when the case is going to be counseled for best treatment options.

\section{References}

[1] Abbasi A, Bhutto AR, Butt N, Munir SM. Correlation of serum alpha fetoprotein and tumor size in hepatocellular carcinoma. J Pak Med Assoc 2012; vol. 62, No. 1 January.

[2] Belghiti J, Cortes A, Abdalla EK, Regimbeau JM, Prakash K. Resection prior to liver transplantation for hepatocellular carcinoma. Ann Surg. 2003; 238: 885892.

[3] Belghiti J. Transplantation for liver tumors.SeminOncol 2005; 32: 29-32.

[4] Bruix $J$ and Sherman $M$. Practice Guidelines Committee, American Association for the Study of Liver Diseases. Management of hepatocellular carcinoma.Hepatology 2005; 42: 1208-1236.

[5] Choti MA. Transplantation versus resection for hepatocellular carcinoma in the mild cirrhotic: framing the debate. J Gastrointest Surg. 2009; 13:1021-1022.

[6] De Luna W, Sze DY, Ahmed A, Ha BY, Ayoub W, Keeffe EB, Cooper A, EsquivelC,NguyenMH.Transarterialchemoinfusion for hepatocellular carcinoma as downstaging therapy and a bridge toward liver transplantation.Am J Transplant 2009; 9: $1158-1168$

[7] El-Serag $\boldsymbol{H B}$ and Rudolph $\boldsymbol{K} \boldsymbol{L}$. Hepatocellular carcinoma: epidemiology and molecular carcinogenesis.
Gastroenterology 2007; 132: 2557-76.

[8] El-Serag HB, Tran T, Everhart JE. Diabetes increases the risk of chronic liver disease and hepatocellular carcinoma. Gastroenterology 2007; 126:460-8.

[9] El-Serag HB.Epidemiology of hepatocellular carcinoma.Clin Liver Dis 2001; 5: 87-107.

[10]El-Serag HB.Hepatocellular carcinoma. N Engl J Med. 2011; 365(12):1118- 1127.

[11]European Association for the Study of the Liver (EASL) - European Organisation for Research and Treatment of Cancer (EORTC). Clinical Practice Guidelines: Management of hepatocellular carcinoma. Journal of Hepatology. 2012; 56 j: 908-943.

[12]Facciuto ME, Rochon C, Pandey M, RodriguezDavalos M, Samaniego S, Wolf DC, Kim-Schluger L, Rozenblit G, Sheiner PA. Surgical dilemma: liver resection or liver transplantation for hepatocellular carcinoma and cirrhosis. Intention-to-treat analysis in patients within and outwith Milan criteria. HPB (Oxford) 2009; 11(5):398- 404.

[13] Huo TI, Lin HC, Hsia CY, Wu JC, Lee PC, Chi CW, Lee SD. The model for end-stage liver disease based cancer staging systems are better prognostic models for hepatocellular carcinoma: a prospective sequential survey. Am J Gastroenterol 2004; 102:1920-1930.

[14]Kumar CS, Fausto N, Robbins L, Abbas Abul K. Robbins and Cotran pathologic basis of disease.2008(7th ed.). St. Louis, MO: Elsevier Saunders. p. 878.

[15] Majno PE, Adam R, Bismuth H, Castaing D, Ariche A, Krissat $\mathbf{J}$. Influence of preoperative transarteriallipiodol chemoembolization on resection and transplantation for hepatocellular carcinoma in patients with cirrhosis. Ann Surg 1997; 226:688-701.

[16] Mohamed NH, El-Zawahry, Mokbtar A, Mokbtar NM, El-Mawla NG. Review of epidemiologic and clinicopathologic features of 403 hepatocellular carcinoma (HCC) patients. Journal of the Egyptian Nat Cancer Inst. 2000;12(2): 87-93.

[17] Nagasue N, Ogawa Y, Yukaya H, Ohta N, Ito A. Serum levels of estrogens and testosterone in cirrhotic men with and without hepatocellular carcinoma. Gastroenterology.1985; 88: 768-772.

[18] Nordenstedt $\mathrm{H}$, White DL, El-Serag HB. The changing pattern of epidemiology in hepatocellular carcinoma, Digestive and Liver Disease 2010; 42: 3: 206- 214.

[19] Omar A, Abou-Alfa G K, Khairy A, Omar H. Risk factors for developing hepatocellular carcinoma in Egypt. Chin ClinOncol 2013; 2(4): 43-51.

[20]Ravaioli M, Grazi GL, Piscaglia F, Trevisani F, Cescon M, Ercolani G, Vivarelli $M$, Golfieri $R$, D'ErricoGrigioni A, Panzini I, Morelli C, Bernardi M, Bolondi L, Pinna AD. Liver transplantation for hepatocellular carcinoma: results of down-staging in patients initially outside the Milan selection criteria. Am J Transplant 2008; 8: 2547-2557.

[21] Sangiovanni A, Prati GM, Fasani P, Ronchi G, Romeo R, Manini M, Del Ninno E, Morabito A, Colombo M. The natural history of compensated cirrhosis due to hepatitis C virus: a 17 -year cohort study of 214 patients. Hepatology 2006;43:1303-1310.

[22] Schwartz M, Roayaie S, Konstadoulakis M. Strategies for the management of hepatocellular carcinoma.Nature Clinical Practice Oncology. 2007;4, 424-432 


\section{International Journal of Science and Research (IJSR) \\ ISSN (Online): 2319-7064}

Index Copernicus Value (2015): 78.96 | Impact Factor (2015): 6.391

[23] Shaker MK, Abdella HM, Khalifa MO, El Dorry AK. Epidemiological characteristics of hepatocellular carcinoma in Egypt: a retrospective analysis of 1313 cases. Liver Int. 2013 Nov;33(10):1601-6.

[24] Velazquez, RE, Rodriguez, M, Navascues CA, Linares A, Perez R, Sotorries NG, Martinez I, Rodrigo L. Prospective analysis of risk factors for hepatocellular carcinoma in patients with liver cirrhosis. Hepatology 2003; 37:520-527

[25] Weledji EP,Orock GE, Ngowe MN, andNsagha DS. How grim is hepatocellular carcinoma? Ann Med Surg(Lond). 2014 Sep; 3(3): 71-76.

[26] World Health Organization, International Agency for Research on Cancer.GLOBOCAN 2008.(http://globocan.iarc.fr.)

[27] Yang, JD and Roberts LR. Hepatocellular carcinoma: a global view. Nature Reviews Gastroenterology and Hepatology 2010 vol. 7, 448-458.

[28] Yu MW, Yeh SH, Chen PJ, Liaw YF, Lin CL, Liu CJ. Hepatitis B virus genotype and DNA level and hepatocellular carcinoma: a prospective study in men. $\mathrm{J}$ Natl Cancer Inst 2005; 97:265-272.

Volume 6 Issue 7, July 2017 www.ijsr.net 